\title{
GENOME-WIDE DNA METHYLATION PATTERNS IN SUICIDE VICTIMS: IDENTIFICATION OF NEW CANDIDATE GENES
}

\author{
Katarina Kouter ${ }^{1}$, Tomaž Zupanc ${ }^{2}$ \& Alja Videtič Paska ${ }^{1}$ \\ ${ }^{I}$ Medical Centre for Molecular Biology, Institute of Biochemistry, Faculty of Medicine, \\ University of Ljubljana, Ljubljana, Slovenia \\ ${ }^{2}$ Institute of Forensic Medicine, Faculty of Medicine, University of Ljubljana, Ljubljana, Slovenia
}

received: 20.8.2019;

revised: 19.9.2019;

accepted: 27.9.2019

\section{SUMMARY}

Suicide is a major global public health problem with significant impact on society. According to the World Health Organization, every year about 800.000 people commit suicide, while at the global level suicide accounts for $50 \%$ of all violent deaths among men and for $71 \%$ among women. Suicide is a complex phenomenon which cannot be attributed to a single causal factor, but to a combination of simultaneous effects of multiple factors which are expressed in the form of psychological, biological and sociological indicators. Analysis of epigenetic mechanisms (methylation of the DNA, modifications of histone proteins and (networks of) miRNA), which link the interaction between genes and the environment, could importantly contribute to better understanding of suicidal behaviour. Recent studies on suicidal behaviour and DNA methylation show differences in DNA methylation pattern, with numerous sites among suicide victims. Using next generation sequencing, genome-wide studies helped identify novel candidate genes while studies of already known candidate genes (such as glucocorticoid receptor and BDNF) gave us better insight into the interplay of genetics and epigenetics.

Epigenetic studies importantly contribute to elucidation of new biomarkers for suicidal behaviour. However, present studies are very different in design and often performed on very small samples, and these limitations could be overcome with more careful study preparation.

Key words: suicidal behaviour - epigenetics - DNA methylation

$* * * * *$

\section{INTRODUCTION}

Suicide is a major public health problem imposing significant impact on all societies, but better understanding of suicide risk factors can importantly contribute to suicide prevention (Turecki et al. 2012). Every year close to 800.000 people lose their life to suicide, and the suicide attempt rate is estimated to be more than twenty times higher (WHO 2018). At the global level suicide accounts for $50 \%$ of all violent deaths among men and for $71 \%$ among women (WHO 2014). The risk factors for suicide and suicidal behaviour can be divided between two levels: proximal and distal. Proximal risk factors act as triggers for suicidal behaviour, and among them the strongest association has been determined for the onset of psychopathology. On the other hand distal risk factors, such as family history of suicide, genetic predisposition and early-life adversity, increase predisposition for suicidal behaviour (Turecki 2014). The molecular studies of suicidal behaviour began in the 1970s when the team of Marie Åsberg found lower levels of 5hydroxyindoleacetic acid in the cerebrospinal fluid of suicide victims who used violent suicide methods (Asberg et al. 1976). Further family, twin and adoption studies showed that a significant proportion of suicide ideation, suicide attempt and also suicide can be influenced by genetics (Bondy et al. 2006, Brent \& Mann 2005, Marusic \& Farmer 2001). After sequencing the human genome in 2001 the exponential growth of genetic studies of suicidal behaviour began, and the most widely studied have been the single nucleotide polymorphisms. Significant associations have been determined for several genes, among which the most powerful have been determined for the genes coding proteins involved in the serotonergic system (like serotonin transporter and receptors), enzyme catecholO-methyltransferase (COMT) (Bondy et al. 2006), and also gene coding for brain-derived neurotropic factor (BDNF) (Gonzalez-Castro et al. 2017). Comprehensive genome-wide association studies revealed new candidate genes for suicidal behaviour (Zai et al. 2012), but understanding of molecular-genetic mechanisms of suicidal behaviour remained rather limited. As suicidal behaviour is importantly affected by environmental stimuli, epigenetic mechanisms, particularly DNA methylation, is becoming one of the leading fields in contemporary research, promising deeper understanding of molecular origin of suicidal behaviour.

This article was presented at the $7^{\text {th }}$ Biennial Cambridge International Conference on Mental Health,

Cambridge, 5-6 ${ }^{\text {th }}$ September 2019 


\section{EPIGENETICS}

Epigenetics can help us understand the delicate interlacing of the environmental and genetic influences inside the cell. The term "epigenetics" is used to describe the often heritable changes in gene expression; the catch being that this changes do not originate from a difference in DNA sequence (Diaz de Leon-Guerrero et al. 2011). Epigenetic regulation is crucial during the developmental period of an organism and plays an important part in adulthood as well (Chen et al. 2017). Showing high tissue specificity, it enables different cells in our body to maintain their identity and adapt to stimuli. The epigenetic state of a cell is thus partially reversible and can be morphed according to the signals the cell receives (Jaenisch \& Bird 2003).

There are multiple mechanisms by which epigenetic regulation displays its effects; non-coding RNAs, histone modification and DNA methylation (Allis \& Jenuwein 2016).

Among epigenetic mechanisms, DNA methylation is the most widely studied, and has been so far associated to different psychiatric disorders such as major depressive disorder (Brown et al. 2019), schizophrenia (Pries et al. 2017), and suicide (Roy \& Dwivedi 2017). In the process of DNA methylation, one methyl group is added on the $5 \mathrm{C}$ position of a cytosine. A single cytosine can therefore be fully methylated of fully unmethylated, depending on whether the methyl group is bound or not (Prokhortchouk \& Defossez 2008). Enzymes preforming this operation are DNA methyltransferases (DNMT) and the donor of methyl group is S-adenosylmethionine (Lyko 2017). The binding of methyl group to the cytosine is covalent, making it stable even in post mortem state (Bestor 2000). Some members of DNA methyltrasferases maintain the methylation pattern of newly divided cells (DNMT1) while others have the ability to perform de novo methylation of previously unmethylated cytosines (DNMT3A and DNMT3B) (Lyko 2017). Contrary to de novo methylation, passive or active demethylation is also possible. In passive demethylation DNA replication is not followed by methylation, so the old methylation pattern does not stay conserved (Guo et al. 2014). Active demethylation is carried by a family of TET enzymes (ten-eleven translocation, named after the translocation between chromosome 10 and 11) and thymine DNA glycosylase (TDG) enzyme. Methylated cytosines are replaced with unmethylated cytosines via processes of oxidation, excision and repair mechanism (Kohli \& Zhang 2013).

Methylated cytosines can usually be found in cytosine-phosphate-guanine DNA motives, also called CpGs. Regions of DNA that contain high frequency of $\mathrm{CpG}$ motives are called $\mathrm{CpG}$ islands and usually exhibit a regulatory role. There are approximately 28 million CpGs in the human genome, forming 45 thousand $\mathrm{CpG}$ islands (Deaton \& Bird 2011). Often they are located in promoter region and can serve as binding sites for various transcription factors (Illingworth \& Bird 2009).
DNA methylation can effect gene expression using two mechanisms. First, bound methyl groups can obstruct activators of transcription, such as transcription factors, from binding to DNA (Lee et al. 2014). Second, methyl-CpG binding domain (MBD) proteins are a family of proteins that preferentially bind to methylated cytosines. When bound, they recruit additional protein leading to epigenetic remodelling and transcriptional repression (Du et al. 2015).

DNA methylation is pivotal for maintaining basic cellular processes and synaptic plasticity in the central nervous system, affecting cognition (Bird 2002). Some drugs, used in treatment of neuropsychiatric disorders, can potentially be associated with DNA methylation. The studies were carried out primarily on animal models and human cell lines, but they indicate the involvement of drugs in the treatment of bipolar disorder, schizophrenia, and depression (Mill et al. 2008, Melka et al. 2014, Asai et al. 2013, Le Francois et al. 2015, Wei et al. 2014).

This all speaks to the need to further investigate the role of epigenetic regulation in the aetiology of psychiatric disorders, including suicidal behaviour.

\section{DNA METHYLATION OF CANDIDATE GENES FOR SUICIDAL BEHAVIOUR}

Initial finding that has triggered the DNA methylation studies of psychiatric disorders was probably the study on glucocorticoid receptor gene methylation in association of maternal care and its influences on the hypothalamic-pituitary-adrenal (HPA) function. Namely, different levels of DNA methylation that associated with gene expression and response to stress were observed among two groups of rats that differed in the frequency of licking and grooming of their offspring (Turecki et al. 2012). The results of the animal model were further investigated also on humans, particularly suicide victims with and without history of childhood abuse, and similar differences as in the animal study were observed (McGowan et al. 2009)

Another important candidate gene in the moleculargenetic studies of suicidal behaviour is BDNF. It is involved in synaptic plasticity modulation (Bibel \& Barde 2000), and it influences several neural processes during the development, like neurogenesis, neuronal survival and maturation of neural development pathways (Russo-Neustadt 2003). Structural abnormalities of the central neuronal system, like reduced neural plasticity and impaired stress response could be associated to changes in the BDNF regulation (Dwivedi 2012). We have performed a study on brain tissue samples of suicide completers, and we showed that methylation pattern of the promoter/exon IV associated with the BDNF expression. Namely, higher methylation levels and lower mRNA expression were observed in suicide victims compared to the controls (Keller et al. 2010). Furthermore, global methylation levels were not associated with suicide completion, or with sex and age. This finding additionally supported the obtained results that 
linked the methylation state of BDNF promoter/exon IV to suicide particularly (Keller et al. 2010). Our further research on one of the BDNF receptors, the tropomyosin-related kinase B (NTRK2), however, did not show the correlation between the levels of mRNA expression and methylation status (Keller et al. 2011).

There are a few more studies of suicide and candidate gene methylation where increased DNA methylation and decreased gene expression were observed: $\gamma$-aminobutyric acid (GABA)A receptor $\alpha 1$ subunit (Poulter et al. 2008), NTRK2 (Ernst et al. 2009), and spermine oxidase (SMOX) (Fiori \& Turecki 2010). Several other candidate genes, like ErbB3 (Mahar et al. 2017) and kappa opioid receptor (Lutz et al. 2018) have shown a significant potential for association with suicide.

More extensive table of studies on DNA methylation, suicidal behaviour, and also major depressive disorder as one the most comorbid psychiatric diagnosis can be found in the review paper (Roy \& Dwivedi 2018).

\section{SUICIDAL BEHAVIOUR AND GENOME-WIDE DNA METHYLATION STUDIES}

As next generation sequencing methodology bloomed, sequencing became faster and thus making whole genome analyses attainable. So far multiple genomewide studies were conducted. In one of the first researchers looked at potentially altered methylation pattern in hippocampus of male suicide victims and control group. They identified 366 promoter regions showing differential methylation, majority of them being hypermethylated. Many of promoters were associated with genes involved in cognitive processes (Labonte et al. 2013). Another popular brain area of interest is prefrontal cortex. Male and female suicide victim with major depressive disorder showed greater levels of methylation in ventral prefrontal cortex compared to a major depressive disorder free control group (Haghighi et al. 2014). Another study was made on prefrontal cortex of male suicide victims and control group. Looking at single $\mathrm{CpGs}$ over the genome, they observed lower levels of methylation while specific parts showed elevated levels of methylation. As the study sample number was low, no gene remained statistically associated with suicidal behaviour after genome-wide multiple testing correction. Still, ontology analysis highlighted enrichment of genes involved in transcription regulation (Schneider et al. 2015). Astrocytes are glial cells, performing various functions from blood-brain barrier support to trauma repair. When looking at methylation pattern of male suicide victims showing downregulation of astrocytic markers, a lower level of methylation of broader regions could be observed (Nagy et al. 2015). One study compared methylation pattern of two cortical brain regions between depressed suicide completers and control group. They observed a few gene regions showing significant differences in methylation levels. Surprisingly a potential candidate gene
PSORS1C3 (psoriasis susceptibility 1 candidate 3) showed hypomethylation across all $\mathrm{CpG}$ sites of interest in both brain regions (Murphy et al. 2017).

We conducted a genome-wide study as well, observing DNA methylation pattern in hippocampus and a prefrontal cortical region, Brodmann area 9. The study group consisted of male suicide victims who died by hanging and control group. Similarly, to other studies mentioned we determined several differences in methylation level between suicide victims and controls in both brain regions (almost $3000 \mathrm{CpGs}$ with $>25 \%$ difference in methylation and q-value $<0.01$ ). The gene ontology analysis showed enrichment for terms associated with cell structural integrity and nervous system regulation, which are both important players in brain plasticity. Additional gene expression analysis identified changes in two potentially regulatory genes, ZNF714 and NRIP3. Although our analysis was performed on a rather small sample size and on whole tissue, which is comprised of various cells, our results gave an important contribution revealing new potential candidate genes for suicidal behaviour (Kouter et al. 2019).

While post mortem studies enable us great insight into the complex mechanism of the brain, blood could be used as a peripheral tissue available from living subjects as well. Suicidal often presents itself as comorbidity with other psychiatric disorders. In a study researchers compared blood methylation profile between patients with bipolar disorder showing suicidal behaviour and patients who showed no such behaviour. They as well observed differential levels of methylation of multiple genome regions in patients with suicidal behaviour, identifying three potential candidate genes (Jeremian et al. 2017). One of the biggest studies so far observed methylation levels in blood and a subset sample of prefrontal cortex in patients with major depressive disorder. When comparing to psychiatric disorder free control group they observed methylation differences in multiple parts of the genome. What is especially interesting is an overlap of findings between blood and one of the studied brain region (Brodmann area 10), portion of them belonging to genes involved in bran development and function (Aberg et al. 2018).

Whole genome DNA methylation analyses do come with its caveats. First analyses of this type often produce large amounts of data that need bioinformatics expertise for quality data processing. Often numerous single CpGs and larger genomic regions will show differential methylation, which then have to be placed in a broader functional context of a cell. While the price on NGS decreases rapidly the number of samples for wholegenome studies still often remains low. Final question is also whether or not low percent changes in methylation show effect on a biological level. Despite multiple limitations whole genome analyses serve as a great tool for the search of new candidate gene. They give insight into otherwise hidden parts of genome which often get overlooked as numerous studies focus on specific candidate genes only. 


\section{CONCLUSIONS}

Suicidal behaviour is a complex phenomenon, influenced by environmental factors and multiple genes, and the interaction between them could be linked with epigenetic mechanisms. Both, animal models and studies on human samples have revealed important changes in DNA methylation patterns of genes that are potentially associated with suicidal behaviour, like glucocorticoid receptor gene, BDNF, and other genes determined by whole epigenome analyses. Although DNA methylation studies are strongly outnumbered by single nucleotide polymorphisms studies, the results of epigenetic analyses are already importantly supporting current knowledge on molecular pathways tied to suicidal behaviour. Further studies of other epigenetic mechanisms, posttranslational modifications of histone protein and non-coding RNA (miRNA and long noncoding RNA), will most likely contribute to understanding of molecular-genetic background of suicidal behaviour even more.

\section{Acknowledgements:}

This work was supported by the Slovenian Research Agency: Program grant No. P1-0390, Research project J3-7132, and Young researcher grant.

\section{Conflict of interest: None to declare.}

\section{Contribution of individual authors:}

Alja Videtič Paska wrote Candidate genes analysis. Katarina Kouter wrote the Whole genome analysis.

Katarina Kouter \& Alja Videtič Paska wrote the Introduction, Epigenetics and Conclusions.

Katarina Kouter, Tomaž Zupanc \& Alja Videtič Paska wrote review and editing.

All authors have read, reviewed and approved the manuscript.

\section{References}

1. Aberg KA, Dean B, Shabalin AA, Chan RF, Han LKM, Zhao M, et al.: Methylome-wide association findings for major depressive disorder overlap in blood and brain and replicate in independent brain samples. Mol Psychiatry 2018. Epub ahead of print

2. Allis $C D \&$ Jenuwein T: The molecular hallmarks of epigenetic control. Nature Reviews Genetics 2016; 17:487

3. Asai $T$, Bundo $M$, Sugawara $H$, Sunaga $F$, Ueda J, Tanaka $G$, et al.: Effect of mood stabilizers on DNA methylation in human neuroblastoma cells. Int $J$ Neuropsychopharmacol 2013; 16:2285-94

4. Asberg M, Traskman L \& Thoren P: 5-HIAA in the cerebrospinal fluid. A biochemical suicide predictor? Arch Gen Psychiatry 1976; 33:1193-7

5. Bestor TH: The DNA methyltransferases of mammals. Hum Mol Genet 2000; 9:2395-402
6. Bibel $M \&$ Barde YA: Neurotrophins: key regulators of cell fate and cell shape in the vertebrate nervous system. Genes Dev 2000; 14:2919-37

7. Bird A: DNA methylation patterns and epigenetic memory. Genes Dev 2002; 16:6-21

8. Bondy B, Buettner A \& Zill P: Genetics of suicide. Mol Psychiatry 2006; 11:336-51

9. Brent DA \& Mann JJ: Family genetic studies, suicide, and suicidal behavior. Am J Med Genet C Semin Med Genet 2005; 133C:13-24

10. Brown A, Fiori LM \& Turecki G: Bridging Basic and Clinical Research in Early Life Adversity, DNA Methylation, and Major Depressive Disorder. Front Genet 2019; 10:229

11. Chen Z, Li S, Subramaniam S, Shyy JY-J \& Chien S: Epigenetic Regulation: A New Frontier for Biomedical Engineers. Annual Review of Biomedical Engineering 2017; 19:195-219

12. Deaton $A M \&$ Bird $A: C p G$ islands and the regulation of transcription. Genes \& development 2011; 25:1010-22

13. Diaz De Leon-Guerrero S, Pedraza-Alva G \& PerezMartinez L: In sickness and in health: the role of methyl$C p G$ binding protein 2 in the central nervous system. Eur $J$ Neurosci 2011; 33:1563-74

14. Du Q, Luu P-L, Stirzaker C \& Clark SJ: Methyl-CpGbinding domain proteins: readers of the epigenome. Epigenomics 2015; 7:1051-73

15. Dwivedi Y 2012. Brain-Derived Neurotrophic Factor in Suicide Pathophysiology. In: Dwivedi, Y. (ed.) The Neurobiological Basis of Suicide. Boca Raton (FL)

16. Ernst C, Deleva V, Deng X, Sequeira A, Pomarenski A, Klempan $T$, et al.: Alternative splicing, methylation state, and expression profile of tropomyosin-related kinase $B$ in the frontal cortex of suicide completers. Arch Gen Psychiatry 2009; 66:22-32

17. Fiori LM \& Turecki G: Genetic and epigenetic influences on expression of spermine synthase and spermine oxidase in suicide completers. Int J Neuropsychopharmacol 2010; 13:725-36

18. Gonzalez-Castro TB, Salas-Magana M, Juarez-Rojop IE, Lopez-Narvaez ML, Tovilla-Zarate CA \& Hernandez-Diaz $Y$ : Exploring the association between BDNF Val66Met polymorphism and suicidal behavior: Meta-analysis and systematic review. J Psychiatr Res 2017; 94:208-17

19. Guo F, Li X, Liang D, Li T, Zhu P, Guo H, et al.: Active and passive demethylation of male and female pronuclear DNA in the mammalian zygote. Cell Stem Cell 2014; 15:447-59

20. Haghighi F, Xin Y, Chanrion B, O'donnell AH, Ge Y, Dwork AJ, et al.: Increased DNA methylation in the suicide brain. Dialogues Clin Neurosci 2014; 16:430-8

21. Illingworth RS \& Bird AP: CpG islands--'a rough guide'. FEBS Lett 2009; 583:1713-20

22. Jaenisch $R$ \& Bird A: Epigenetic regulation of gene expression: how the genome integrates intrinsic and environmental signals. Nat Genet 2003; 33 Suppl:245-54

23. Jeremian $R$, Chen YA, De Luca V, Vincent JB, Kennedy $J L$, Zai CC, et al.: Investigation of correlations between DNA methylation, suicidal behavior and aging. Bipolar Disord 2017; 19:32-40

24. Keller S, Sarchiapone M, Zarrilli F, Tomaiuolo R, Carli V, Angrisano T, et al.: TrkB gene expression and DNA methylation state in Wernicke area does not associate with suicidal behavior. J Affect Disord 2011; 135:400-4 
25. Keller S, Sarchiapone M, Zarrilli F, Videtic A, Ferraro A, Carli $V$, et al.: Increased BDNF promoter methylation in the Wernicke area of suicide subjects. Arch Gen Psychiatry 2010; 67:258-67

26. Kohli RM \& Zhang Y: TET enzymes, TDG and the dynamics of DNA demethylation. Nature 2013; 502:472-9

27. Kouter K, Zupanc T \& Videtic Paska A: Genome-wide DNA methylation in suicide victims revealing impact on gene expression. J Affect Disord 2019; 253:419-25

28. Labonte B, Suderman M, Maussion G, Lopez JP, NavarroSanchez L, Yerko V, et al.: Genome-wide methylation changes in the brains of suicide completers. Am J Psychiatry 2013; 170:511-20

29. Le Francois B, Soo J, Millar AM, Daigle M, Le Guisquet $A M$, Leman $S$, et al.: Chronic mild stress and antidepressant treatment alter 5-HT1A receptor expression by modifying DNA methylation of a conserved Sp4 site. Neurobiol Dis 2015; 82:332-41

30. Lee CJ, Evans J, Kim K, Chae H \& Kim S: Determining the effect of DNA methylation on gene expression in cancer cells. Methods Mol Biol 2014; 1101:161-78

31. Lutz PE, Almeida D, Belzeaux R, Yalcin I \& Turecki G: Epigenetic regulation of the kappa opioid receptor gene by an insertion-deletion in the promoter region. Eur Neuropsychopharmacol 2018; 28:334-40

32. Lyko F: The DNA methyltransferase family: a versatile toolkit for epigenetic regulation. Nature Reviews Genetics 2017; 19:81

33. Mahar I, Labonte B, Yogendran S, Isingrini E, Perret L, Davoli MA, et al.: Disrupted hippocampal neuregulin1/ErbB3 signaling and dentate gyrus granule cell alterations in suicide. Transl Psychiatry 2017; 7:e1161

34. Marusic $A \&$ \& Farmer A: Genetic risk factors as possible causes of the variation in European suicide rates. British Journal of Psychiatry 2001; 179:194-6

35. Mcgowan PO, Sasaki A, D'alessio AC, Dymov S, Labonte $B$, Szyf $M$, et al.: Epigenetic regulation of the glucocorticoid receptor in human brain associates with childhood abuse. Nat Neurosci 2009; 12:342-8

36. Melka MG, Castellani CA, Rajakumar N, O'reilly $R \&$ Singh SM: Olanzapine-induced methylation alters cadherin gene families and associated pathways implicated in psychosis. BMC Neurosci 2014; 15:112

37. Mill J, Tang T, Kaminsky Z, Khare T, Yazdanpanah S, Bouchard L, et al.: Epigenomic profiling reveals DNAmethylation changes associated with major psychosis. Am J Hum Genet 2008; 82:696-711

38. Murphy TM, Crawford B, Dempster EL, Hannon E, Burrage J, Turecki G, et al.: Methylomic profiling of cortex samples from completed suicide cases implicates a role for PSORS1C3 in major depression and suicide. Transl Psychiatry 2017; 7:e989

39. Nagy C, Suderman M, Yang J, Szyf M, Mechawar N, Ernst $C$, et al.: Astrocytic abnormalities and global DNA methylation patterns in depression and suicide. Mol Psychiatry 2015; 20:320-8

40. Poulter MO, Du L, Weaver IC, Palkovits M, Faludi G, Merali $Z$, et al.: GABAA receptor promoter hypermethylation in suicide brain: implications for the involvement of epigenetic processes. Biol Psychiatry 2008; 64:645-52

41. Pries LK, Guloksuz $S$ \& Kenis G: DNA Methylation in Schizophrenia. Adv Exp Med Biol 2017; 978:211-36

42. Prokhortchouk E \& Defossez PA: The cell biology of DNA methylation in mammals. Biochim Biophys Acta 2008; 1783:2167-73

43. Roy B \& Dwivedi Y: Understanding epigenetic architecture of suicide neurobiology: A critical perspective. Neuroscience and biobehavioral reviews 2017; 72:10-27

44. Roy B \& Dwivedi Y: Understanding the Neuroepigenetic Constituents of Suicide Brain. Prog Mol Biol Transl Sci 2018; 157:233-62

45. Russo-Neustadt A: Brain-derived neurotrophic factor, behavior, and new directions for the treatment of mental disorders. Semin Clin Neuropsychiatry 2003; 8:109-18

46. Schneider E, El Hajj N, Muller F, Navarro B \& Haaf T: Epigenetic Dysregulation in the Prefrontal Cortex of Suicide Completers. Cytogenet Genome Res 2015; 146:19-27

47. Turecki G: The molecular bases of the suicidal brain. Nat Rev Neurosci 2014; 15:802-16

48. Turecki G, Ernst C, Jollant F, Labonte B \& Mechawar N: The neurodevelopmental origins of suicidal behavior. Trends Neurosci 2012; 35:14-23

49. Wei Y, Melas PA, Wegener G, Mathe AA \& Lavebratt C: Antidepressant-like effect of sodium butyrate is associated with an increase in TET1 and in 5-hydroxymethylation levels in the Bdnf gene. Int J Neuropsychopharmacol 2014; 18

50. Worl Helath Organization: 2014. Preventing suicide. A global imperative.

51. World Helath Organization: 2018. National suicide prevention strategies: progress, examples and indicators., Geneva: World Health Organization, Licence: CC BYNC-SA 3.0 IGO

52. Zai CC, De Luca V, Strauss J, Tong RP, Sakinofsky I \& Kennedy JL 2012. Genetic Factors and Suicidal Behavior. In: Dwivedi, Y. (ed.) The Neurobiological Basis of Suicide. Boca Raton (FL)

Correspondence:

Assoc. Prof. Alja Videtič Paska, MD

University of Ljubljana, Faculty of Medicine, Institute of Biochemistry

Vrazov trg 2, SI-1000 Ljubljana, Slovenia

E-mail:alja.videtic@mf.uni-lj.si 